\title{
Effects of the Neurodevelopmental Treatment (NDT) on the Mobility of Children with Cerebral Palsy
}

\author{
Thomas Besios', Aggeloussis Nikolaos ${ }^{2}$, Gourgoulis Vassilios', \\ Mauromatis Giorgos ${ }^{2}$, Yannis Tzioumakis ${ }^{3}$, Nikos Comoutos ${ }^{3}$ \\ ${ }^{1}$ Department of Physical Education and Sport Science, Democritus University of Thrace, Komotini, Greece \\ ${ }^{2}$ Department of Physical Education and Sport Science, Democritus University of Thrace, Orestiada, Greece \\ ${ }^{3}$ Department of Physical Education and Sport Science, University of Thessaly, Lamia, Greece \\ Email: tombesios@yahoo.gr
}

How to cite this paper: Besios, T., Nikolaos, A., Vassilios, G., Giorgos, M., Tzioumakis, Y. and Comoutos, N. (2018) Effects of the Neurodevelopmental Treatment (NDT) on the Mobility of Children with Cerebral Palsy. Open Journal of Therapy and Rehabilitation, 6, 95-103.

https://doi.org/10.4236/ojtr.2018.64009

Received: October 28, 2018

Accepted: November 27, 2018

Published: November 30, 2018

Copyright $\odot 2018$ by authors and Scientific Research Publishing Inc. This work is licensed under the Creative Commons Attribution International License (CC BY 4.0).

http://creativecommons.org/licenses/by/4.0/

(c) $\underset{\mathrm{EY}}{\mathrm{C}}$ Open Access

\begin{abstract}
The purpose of the present study was to examine the effectiveness of the NDT method (Bobath) in children with CP. Twenty children with cerebral palsy (7 with quadriplegia, 6 with diplegia and 7 with right hemiplegia), with mean age of $4.85 \pm 2.49$ years, took part in the study. Materials-Method: The children participated in an intervention that consisted of an 8-week Bobath program. GMFM-88, PEDI and TUG scores were measured across three time points during the intervention (a baseline measurement, a second at the end of the intervention and a post-intervention measurement one month after the end of the intervention). Results: The results of the NDT intervention showed that the participant children significantly improved their GMFM-88 and TUG scores between initial and final measurement and maintained this one month later $\left(\mathrm{F}_{2,36}=69,778, \mathrm{p}<0.001\right)$, while in PEDI the intervention program had no statistically significant effect $\left(\mathrm{F}_{2,36}=0.844, \mathrm{p}=0.438\right)$. In conclusion, there is strong evidence of the effectiveness of the NDT (Bobath) method in improving the mobility of children regardless of the frequency of its application.
\end{abstract}

\section{Keywords}

Bobath, NDT, Cerebral Palsy, Hemiplegia, Children

\section{Introduction}

Medical literature provides several definitions describing the condition of Cerebral Palsy (CP). Bobath (1965) [1] describes CP as a sensorimotor dysfunction. 
Specifically, they describe CP "not as a simple illness, but as a set of conditions caused by brain damage". Potential factors accounting for the disorder may be sought during intrauterine or perinatal period. Impairments are permanent and do not evolve over time. Also, CP leads to motor dysfunction accompanied (but not necessarily) by sensory dysfunction [1] (Bobath, 1965).

One of the most common conditions associated with CP is mental retardation. In general, these two conditions tend to co-exist very often, as high risk factors associated with motor dysfunction may predispose to mental retardation. In spastic diplegia, mental retardation is an accompanying finding in $15 \%$ of the preterm and in the $45 \%$ of the term infants. It is also reported that the severity of the sensory disability is associated with more severe forms of impairment. Also, the likelihood for severe mental retardation is increased with conditions of $\mathrm{CP}$ affecting mainly upper limbs [2] (Ferry, 1981).

Studies have shown that there is an increased likelihood for CP associated with preterm infants as well as with low birth weight $(<1500 \mathrm{~g})$, [3] (Sommerfelt, 1997) and also in twin pregnancies, the CP rate is 9.7 per 1000 births [4] (Jian-meng et al., 2000).

Odding, Roebroeck and Stam, (2006) [5] report that in first world countries, $\mathrm{CP}$ rate is 3.3 per 1000 births of living infants, while in lower income countries the CP rate is 2.08 per 1000 births. Also, in a Miller and Bachrach (1995) study [6], using a strict CP definition, they examined 6,000 infants from 13 geographically defined populations in Europe from 1980 to 1990 and they found that the overall CP rate was 2.08 per 1000 births of living infants.

The main purpose of the neurodevelopmental treatment approach (NDT-Bobath) to children with $\mathrm{CP}$ is to provide them with the greatest possible degree of independence. Secondary aims of NDT include the prevention of abnormal motor patterns and the facilitation of normal motor synergies during every day functional activities [7] (Bly, 1991).

A wealth of research has found that NDT has positive effects on children with $\mathrm{CP}$, although the heterogeneity of these studies does not allow for comparison. For instance, we cannot compare single case studies (Palmer, 1990) [8] with studies with more (e.g.: 2 - 5) participants (DeGangi et al, 1983 [9]; Trahan \& Malouin, 2002) [10], and studies with large samples (e.g. 305 participants; Ozgirgin \& Guler-Uysal, 1998) [11]. Also, the diversity of tests been used to examine CP and the large variation in the conduct of studies, is clearly major obstacle in the comparison of the results between these studies.

\section{Aim}

The aim of the present study is to examine the effects of NDT (Bobath) on the motor ability of children with CP. In addition, we aim to examine whether the rate of motor improvement is associated with the frequency of NDT application on children with $\mathrm{CP}$.

\section{Sample}

For the examination of test reliability and the effects of NDT (Bobath) on child- 
ren with $\mathrm{CP}, 20$ children with $\mathrm{CP}$ ( 7 with quadriplegia, 6 with diplegia and 7 with right hemiplegia) participated (Table 1), with mean age of $4.85( \pm 2.49)$ years, mean height of $1.06( \pm 0.17)$ meters and mean weight of $18.58( \pm 7.50)$ kilograms. The aforementioned children had been diagnosed with $\mathrm{CP}$ by a special neurologist or/and pediatric neurologist. Exclusion criteria were the presence of other dysfunctions as learning disabilities, sensory loss, or suffering from other diseases. Participants that had undergone orthopedic surgery had received medication that affects spasticity, or had received therapeutic treatment schemes other than physiotherapy, were also excluded from the study. The severity levels of $\mathrm{CP}$ were evaluated with the use of the Gross Motor Function Classification System Level (GMFCS). GMFCS tool is used to categorize children with CP into five distinct levels, which are based on functional limitations, according to the degree of their disability. In addition, these children should be able self-initiated movement or assisted (e.g.: hand-held devices) mobility.

All participants were selected through continuous sampling method, which is suitable for similar studies and consists of continuous integration of participants (in case the sample is not sufficient before the initiation of the study) during the

Table 1. Clinical characteristics of children with $\mathrm{CP}$ (age in years, weight in kgr and height in $\mathrm{m}$, disease, GMFCS level).

\begin{tabular}{|c|c|c|c|c|c|c|}
\hline CODE & AGE & WEIGHT & HEIGHT & SYMPTOMS & GMFCS & WALKING \\
\hline $\mathrm{T} \Sigma 01$ & 2.5 & 12 & 0.86 & Tetraplegia & 2 & Independent \\
\hline $\mathrm{X} \Omega 02$ & 7 & 23 & 1.25 & Diplegia & 1 & Independent \\
\hline KO03 & 4 & 16 & 1.03 & Diplegia & 2 & Independent \\
\hline NE04 & 5 & 13 & 1.02 & Diplegia & 1 & Independent \\
\hline$\Sigma \mathrm{I} 05$ & 7 & 26 & 1.24 & Hemiplegia & 1 & Independent \\
\hline $\mathrm{K} \Omega 06$ & 3 & 11 & 0.88 & Hemiplegia & 1 & Independent \\
\hline MA07 & 2 & 11 & 0.85 & Diplegia & 2 & Independent \\
\hline ПА08 & 11 & 23 & 1.30 & Hemiplegia & 2 & Walking aid \\
\hline ГІ09 & 2 & 11 & 0.88 & Tetraplegia & 1 & Independent \\
\hline ПА10 & 6 & 20 & 1.05 & Tetraplegia & 2 & Walking aid \\
\hline MI11 & 3 & 16 & 0.92 & Diplegia & 2 & Independent \\
\hline$\Lambda \mathrm{O} 12$ & 3.5 & 20 & 1.02 & Hemiplegia & 1 & Independent \\
\hline MII13 & 9 & 42 & 1.51 & Tetraplegia & 2 & Independent \\
\hline AP14 & 6 & 17 & 1.05 & Tetraplegia & 3 & Independent \\
\hline $\mathrm{K} \Omega 15$ & 6 & 20 & 1.22 & Hemiplegia & 1 & Independent \\
\hline ПА16 & 3.5 & 15 & 0.95 & Tetraplegia & 2 & Independent \\
\hline $\mathrm{T} \Sigma 17$ & 5.5 & 29 & 1.12 & Tetraplegia & 2 & Independent \\
\hline NT18 & 3.5 & 15 & 1.05 & Diplegia & 2 & Independent \\
\hline$\Lambda \mathrm{A} 19$ & 5 & 18 & 109 & Hemiplegia & 1 & Independent \\
\hline$\Phi \Omega 20$ & 2 & 13 & 0.92 & Hemiplegia & 1 & Independent \\
\hline
\end{tabular}


conduct of the study.

Each participant, was randomly categorized to two groups: Lower frequency intervention CP group (LFICP) and higher frequency intervention CP group (HFICP). Each group consisted of 10 participants. Each participant performance was recorded on a classification card and for post-test reliability examination for GMFM and TUG tests, a camcorder (JVC mini DV) was used to capture testing procedures for all participants.

\section{Materials-Instruments}

Data were obtained with the use of the following instruments:

1) GMFM-88 (Gross Motor Function Measurement) was used to evaluate gross motor function. The GMFM-88 is designed to capture alterations in gross motor function in children with $\mathrm{CP}$. The psychometric properties of the GMFM-88, in terms of reliability according to studies over the past 16 years, are acceptable (Bower \& McLellan, 1996; Boyce et al., 1995) [12] [13].

2) PEDI (Pediatric Evaluation Disability Involvement) was utilized to evaluate disability from a pediatric standpoint. PEDI is a reliable instrument, and results are obtained through questions asked to parents in structured interviews. PEDI evaluated the ability but also the quality of functional mobility in three life tasks: a) Daily activities, b) Mobility, and c) Social/Cognitive.

3) Timed Up and Go test (TUG) (Podsiadlo et al., 1991) [14]. The test is used to determine fall risk and measure the progress of balance, sit to stand, and walking. It uses the time that a person takes to rise from a chair, walk across a three meters line, turn around at the end of the line, walk back to the chair, and sit down.

Prior to the study, all participant children underwent weekly NDT therapy, according to each participant level of disability. The therapy was adapted to the condition of each child, and differences were observed only because of the GMFCS categorization and not due to different therapeutic techniques. All children were treated by NDT accredited physiotherapists with at least five years of experience, and with a minimum of 10 years clinical experience.

\section{Procedure}

Children from both groups (LFICP and HFICP), followed two different intervention protocols with Bobath method. LFICP group received a single, one-hour intervention (Bobath) each week, and HFICP group received an intensive one-hour intervention (Bobath), three times each week. Both interventions had the same duration (eight weeks). At the end of the each intervention (T3), the participants were tested in GMFM-88, PEDI and Timed up-and-go for a second time, and one month after the completion of the interventions, all participants were tested with the same instruments for a third time, to examine the degree to which intervention effects were retained. The performance of all participants was recorded and for the GMFM and TUG tests, testing procedures for all par- 
ticipants for all attempts, were also videotaped with a camcorder (JVC mini DV).

\section{Results}

A two-way ANOVA for repeated measures was conducted to examine the effects of the intervention, with "time" as the repeated factor (T1, T3 \& T4) and the grouping of the participants (LFICP and HFICP) as the independent variable. For multiple comparisons of the means we used the Bonferonni test. Level of significance was set to 0.05 .

\section{- $G M F M-88$}

Table 2 presents means and standard deviations of the scores for LFICP and HFICP groups in GMFM- 88 scale.

The results of the two-way ANOVA $(3 \times 2)$ with repeated measures on "time" and "group" (LFICP and HFICP) as an independent variable, showed no significant interaction between "measurement (time)" and "group" $\left(\mathrm{F}_{2,36}=3858, \mathrm{p}=\right.$ $0.055)$. On the other hand, we found a significant main effect for "measurement (time)" $\left(\mathrm{F}_{2,36}=69,778, \mathrm{p}<0.001\right)$, but no significant effect for "group" $\left(\mathrm{F}_{1,18}=\right.$ 0.032, $\mathrm{p}=0.0860)$. Moreover, Bonferonni multiple comparisons test revealed significant differences between baseline and follow-up measurement $(\mathrm{p}<0.001)$, but no significant difference between post-test and follow-up measurement ( $\mathrm{p}=$ 0.955).

So, as the results revealed, the participant children significantly improved their GMFM-88 scores between baseline and follow-up measurement a month later. Therefore, the intervention had a positive effect on GMFM-88 scores, regardless of the frequency of its application.

\section{- PEDI}

Table 3 presents means and standard deviations of the scores for LFICP and HFICP groups in PEDI scale.

Table 2. Means $( \pm \mathrm{SD})$ of GMFM-88 scale scores, for LFICP group and HFICP group in baseline, post-test and follow-up measurement.

\begin{tabular}{cccc}
\hline Measurement & HFICP & LFICP & Total \\
\hline Baseline & $69.69 \pm 23.22$ & $69.96 \pm 28.45$ & $69.83 \pm 25.27$ \\
Post-test & $79.34 \pm 22.14$ & $75.47 \pm 26.18$ & $77.40 \pm 23.68$ \\
Follow-up & $78.83 \pm 22.01$ & $76.51 \pm 25.94$ & $77.67 \pm 23.44$ \\
\hline
\end{tabular}

Table 3. Means $( \pm \mathrm{SD})$ of PEDI scale scores, for LFICP group and HFICP group in baseline, post-test and follow-up measurement.

\begin{tabular}{cccc}
\hline Measurement & HFICP & LFICP & Total \\
\hline Baseline & $62.80 \pm 25.41$ & $70.30 \pm 27.15$ & $66.55 \pm 25.87$ \\
Post-test & $62.90 \pm 25.41$ & $75.47 \pm 27.31$ & $66.55 \pm 25.95$ \\
Follow-up & $62.80 \pm 25.41$ & $70.60 \pm 27.29$ & $66.70 \pm 25.97$ \\
\hline
\end{tabular}


The results of the two-way ANOVA $(3 \times 2)$ with repeated measures on "measurement (time)" (baseline, post-test and follow-up measurement) and "group" (LFICP and HFICP) as independent variable, showed no significant interaction between "measurement (time)" and "group" $\left(\mathrm{F}_{2,36}=1781, \mathrm{p}=0.183\right)$. We also found a non-significant main effect for "measurement (time)" $\left(\mathrm{F}_{2,36}=0.844, \mathrm{p}=\right.$ $0.438)$, and for "group" $\left(\mathrm{F}_{1,18}=0.409, \mathrm{p}=0.531\right)$.

So, the results indicated that participant children in neither group improved their PEDI scores between baseline and post-test measurement, as well as between baseline and follow-up measurement. Therefore, the intervention had no significant effect on PEDI scores, neither in LFICP nor in HFICP group.

\section{- $T U G$}

Table 4 presents means and standard deviations of the scores for LFICP and HFICP groups in TUG scale.

The results of the two-way ANOVA $(3 \times 2)$ with repeated measures on "measurement (time)" (baseline, post-test and follow-up measurement) and "group" (LFICP and HFICP) as independent variable, showed no significant interaction between "measurement (time)" and "group" $\left(\mathrm{F}_{2,36}=0.017, \mathrm{p}=0.984\right)$. On the other hand, we found a significant main effect for "measurement (time)" ( $\mathrm{F}_{2,36}=$ $11,827, \mathrm{p}<0.001)$, but no significant main effect for "group" $\left(\mathrm{F}_{1,18}=0.211, \mathrm{p}=\right.$ 0.652). Moreover, Bonferonni multiple comparisons test revealed significant differences between baseline and post-test $(\mathrm{p}<0.01)$, between baseline and follow-up measurement $(\mathrm{p}<0.01)$, between post-test and follow-up measurement $(\mathrm{p}<0.05)$

So, as the results revealed, participant children in both groups significantly improved their TUG scores between baseline and post-test measurement and also between post-test and follow-up measurement. Therefore, the intervention had a positive effect on GMFM-88 scores, regardless of the frequency of its application.

So, the results indicated that participant children in neither group improved their PEDI scores between baseline and post-test measurement, as well as between baseline and follow-up measurement. Therefore, the intervention had a positive effect on TUG scores for both groups, regardless of the frequency of its application.

\section{Discussion}

In the present study we investigated the effects of NDT-Bobath method in

Table 4. Means $( \pm S D)$ of TUG scale scores, for LFICP group and HFICP group in baseline, post-test and follow-up measurement.

\begin{tabular}{cccc}
\hline Measurement & HFICP & LFICP & Total \\
\hline Baseline & $16.39 \pm 10.52$ & $18.47 \pm 14.94$ & $17.43 \pm 12.62$ \\
Post-test & $12.18 \pm 7.73$ & $14.27 \pm 12.01$ & $13.22 \pm 9.89$ \\
Follow-up & $11.16 \pm 7.35$ & $13.59 \pm 12.07$ & $12.38 \pm 9.80$ \\
\hline
\end{tabular}


children with CP. The results indicated that in both groups (LFICP and HFICP), participant children significantly improved their GMFM-88 scores between baseline and post-test measurement, and the positive effects of the intervention remained also during follow-up measurement, a month later $\left(\mathrm{F}_{2,36}=69,778, \mathrm{p}<\right.$ 0.001). Therefore, the intervention program had a positive impact, in terms of GMFM-88 scoresregardless of the frequency of its application $\left(\mathrm{F}_{1,18}=0.032, \mathrm{p}=\right.$ 0.0860 ). The findings of the present study are in line with previous studies indicating improvement in gait characteristics (Adams et al., 2000) [15], improvement in GMFM scores after an NDT intervention (Knox \& Evans, 2002) [16], improved balance, posture and gait (Ozgirgin et al., 1998) [11] and positive effect on gait on a case study (Palmer et al., 1990) [17]. Trahan and colleagues (2002) [10] reported that a four-week therapeutic scheme that was implemented four times per week resulted in improved GMFM scores, contrary to our findings. Tsorlakis et al., (2005) [18], in a NDT intervention, reported an outstanding improvement in the functional abilities in the GMFM scores for children in both teams, especially for the children in the HFICP group (5 times a week implementation), which also contrasts our findings. Also, in another study (Herndon et al., 1987) [19], the mobility of children with CP was not significantly improved. These results, obviously refer to a study where the NDT method was still in a developing stage, in contrast to current advancements.

As for TUG scores, the results indicate improved performance for children in both groups between baseline and post-test measurement, as well as between post-test and follow-up measurement, one month later $\left(\mathrm{F}_{2,36}=11,827, \mathrm{p}<\right.$ 0.001). This finding indicates that the intervention program had a positive effect, in terms of TUG scores, regardless of the frequency of its application $\left(\mathrm{F}_{1,18}=\right.$ $0.211, \mathrm{p}=0.652)$. Our findings are in line with the results of a recent study (Gonca et al., 2017) [20], that reported in a NDT intervention improved strength in all torso muscle groups compared with baseline measurement $(\mathrm{p}<0.05)$. The findings of this study underline the contribution of exercises targeting torso strengthening in the improvement of mobility in children with CP.

Our study also reported no significant improvement in PEDI scores, neither between baseline and post-test measurement, nor between baseline and follow-up scores $\left(\mathrm{F}_{2,36}=0.844, \mathrm{p}=0.438\right)$. Therefore, the intervention program had no significant effect for neither HFICP nor for LFICP group $\left(\mathrm{F}_{1,18}=0.409, \mathrm{p}=\right.$ 0.531). The findings are in line with previous study (Knox \& Evans, 2002) [16] which examined the effects (baseline, post-test and follow-up) of NDT intervention in terms of GMFM and PEDI scores. They reported significant improvements in GMFM scores but no significant effects for PEDI scores. On the other hand, the findings of our study contrast the findings of another study (Ketelaar et al., 2001) [21], which reported, after a NDT intervention, improvements in daily activities in terms of PEDI scores, but no significant effects in motor improvement in terms of GMFM scores. Future similar studies should focus on recruiting larger samples of both children with $\mathrm{CP}$ and raters for the evaluation of 
children's' performance and scores, but investigators should also consider recruiting experienced physiotherapists that will apply specific therapeutic protocols with great degree of consistency across all participant children with CP.

\section{Conclusion}

The findings of the present study revealed that NDT method may well improve the mobility of children with $\mathrm{CP}$, regardless of the frequency of its application (Adams et al., 2000 [15]; Knox et al., 2002 [16]; Palmer et al., 1988 [17]), while the present results are in contrast with studies reporting that the effectiveness of the NDT intervention is proportional to the frequency of its application (Tsorlakis et al., 2004 [18]; Trahan et al., 2002 [10]).

\section{Limitation of the Study}

1) As to the sample: the sample was only from a small city of Trikala in Greece as the investigation was carried out there.

2) The Bobath intervention program was carried out from two different physiotherapists.

\section{Conflicts of Interest}

The authors declare no conflicts of interest regarding the publication of this paper.

\section{References}

[1] Bobath, B. (1965) Abnormal Postural Reflex Activity Caused by Brain Lesions. Aspen Publication, Rockville, Maryland.

[2] Ferry, P. (1981) On Growing New Neurons: Are Early Intervention Programs Effective. Pediatrics, 67, 38-41.

[3] Sommerfelt, K. (1997) Long-Term Outcome for Non-Handicapped Low Birth Weight Infants: Is the Fog Clearing? European Journal of Pediatrics, 157, 1-3. https://doi.org/10.1007/s004310050755

[4] Liu, J.M., Li, Z.L., Li, Q., Zhao, P., Zhao, F.L., Hong, S.X. and Li, S. (2000) Cerebral Palsy and Multiple Births in China. Epidemiology, 29, 292-299.

[5] Odding, E., Roebroeck, M.E. and Stam, H.J. (2006) The Epidemiology of Cerebral Palsy: Incidence, Impairments and Risk Factors. Disability and Rehabilitation, 28, 183-191. https://doi.org/10.1080/09638280500158422

[6] Miller, F. and Bachrach, S.J. (1995) Cerebral Palsy. A Complete Guide for Caregiving. The Johns Hopkins University Press, Baltimore, London.

[7] Bly, L. (1991) A Historical and Current View of the Basis of NDT. Pediatric Physical Therapy, 3, 131-135. https://doi.org/10.1097/00001577-199100330-00005

[8] Palmer, F.B., Shapiro, B.K., Wachtel, R.C., Allen, M.C., Hiller, J.E. and Harryman, S.E. (1988) The Effects of Physical Therapy on Cerebral Palsy. A Controlled Trial in Infants with Spastic Diplegia. New England Journal of Medicine, 318, 803-808. https://doi.org/10.1056/NEJM198803313181302

[9] DeGangi, G.A. and Royeen, C.B. (1994) Current Practice among Neurodevelopmental Treatment Association Members. The American Journal of Occupational Therapy, 48, 803-809. https://doi.org/10.5014/ajot.48.9.803 
[10] Trahan, J. and Malouin, F. (2002) Intermittent Intensive Physiotherapy in Children with Cerebral Palsy: A Pilot Study. Developmental Medicine of Child Neurology, 44, 233-239.

[11] Ozgirgin, N. and Guler-Uysal, F. (1998) Rehabilitation Outcome in 305 Turkish Patients with Cerebral Palsy. Turkish Journal of Medical Sciences, 28, 67-680.

[12] Bower, E., Mc Lellan, D.L., Arney, J. and Campell, M.J. (1996) A Randomized Controlled Trial of Different Intensities of Physiotherapy and Different Goal-Setting Procedures in 44 Children with Cerebral Palsy. Developmental Medicine of Child Neurology, 36, 226-237.

[13] Boyce, W.F., Gowland, C. and Rosenbaum, P.L. (1995) The Gross Motor Performance Measure: Validity and Responsiveness of a Measure of Quality of Movement. Physical Therapy, 75, 603-613. https://doi.org/10.1093/ptj/75.7.603

[14] Podsiadlo, D. and Richardson, S. (1991) The Timed up and Go Test: A Test of Basic Functional Mobility for Elderly Persons. Journal of American Geriatric Society, 39, 1. https://doi.org/10.1111/j.1532-5415.1991.tb01616.x

[15] Adams, M.A., Chandler, L.S. and Schuhmann, K. (2000) Gait Changes in Children with Cerebral Palsy Following a Neurodevelopmental Treatment Course. Pediatric Physical Therapy, 12, 114-120.

[16] Knox, V. and Evans, A.L. (2002) Evaluation of the Fuctional Effects of a Course of Bobath Therapy in Children with Cerebral Palsy: A Preliminary Study. Developmental Medicine of Child Neurology, 44, 447-460. https://doi.org/10.1111/j.1469-8749.2002.tb00306.x

[17] Palmer, F.B., Shapiro, B.K., Allen, M.C., Mosher, B.S., Bilker, S.A. and Harryman, S.E. (1990) Infant Stimulation Curriculum for Infants with Cerebral Palsy: Effects on Infant Temperament, Parent-Infant Interaction, and Home Environment. Pediatrics, 85, 411-415.

[18] Tsorlakis, N., Evaggelinou, C., Grouios, G. and Tsorbatzoudis, C. (2005) Effect of Intensive Neurodevelopmental Treatment in Gross Motor Function of Children with Cerebral Palsy. Developmental Medicine of Child Neurology, 46, 740-745. https://doi.org/10.1111/j.1469-8749.2004.tb00993.x

[19] Herndon, W.A., Troup, P., Yngve, D.A. and Sullivan, J.A. (1987) Effects of Neurodevelopmental Treatment on Movement Patterns of Children with Cerebral Palsy. Journal of Pediatric Orthopaedics, 7, 395-400. https://doi.org/10.1097/01241398-198707000-00003

[20] Arı, G. and Günel, M.K. (2017) A Randomised Controlled Study to Investigate Effects of Bobath Based Trunk Control Training on Motor Function of Children with Spastic Bilateral Cerebral Palsy. International Journal of Clinical Medicine, 8, 205-215. https://doi.org/10.4236/ijcm.2017.84020

[21] Ketelaar, M., Vermeer, A., Hart, H., van Petegem-van Beek, E. and Helders, P.J. (2001) Effects of a Functional Therapy Program on Motor Abilities of Children with Cerebral Palsy. Physical Therapy, 81, 1534-1545.

https://doi.org/10.1093/ptj/81.9.1534 